\title{
CAPACIDADE NORMATIVA: UN EXERCICIO QUE PON EN FORMA ÁS FACENDAS
}

AUTONÓMICAS?

Araceli de los Ríos Berjillos arios@uloyola.es Marta de Vicente Lama mvicente@uloyola.es Juan Ma Muñoz Tomásjmmtomas@uloyola.es Universidade Loyola Andalucía, C/ Escritor Castilla Aguayo 4 - 14004 Córdoba, España Resumo: A partir da construción de índices analízase o diferente grao de exercicio das competencias normativas sobre tributos cedidos nas CCAA de réxime común. A metodoloxía empregada permite identificar diferenzas existentes entre rexións con respecto á repercusión ou impacto do exercicio da capacidade normativa sobre os beneficios fiscais e, asemade, permite analizar a estabilidade da representatividade das figuras tributarias no período de estudo 2012-2014. As análises indican que as CCAA realizaron un uso intenso malia que dispar da capacidade normativa cedida, pero que este exercicio non altera substancialmente a súa estrutura de ingresos, polo que pouco contribúe á configuración dunha facenda autonómica propia.

Palabras chave: financiamento autonómico, corresponsabilidade fiscal, tributos cedidos, capacidade normativa, beneficios fiscais.

Abstract: In this paper several indexes are designed with the purpose of assessing the existing differences between the Autonomous Communities of Spain as far as exercising their assigned regulatory capacity on taxes. The methodology used in the analysis allows the identification of differences between regions in terms of the impact of the exercise of regulatory capacity on tax benefits and it also allows the analysis of the stability of the representativeness of different taxes throughout the period 2012- 2014. The results indicate that the Spanish Autonomous Communities have made an intensive but uneven use of the exercise of their regulatory capacity, and that this exercise does not substantially alter the configuration of their revenue.

Key words: regional financing, fiscal co-responsibility, assigned taxes, regulatory capacity, tax benefits

\section{INTRODUCIÓN}

Dende que en 1987 se comezara a aplicar o primeiro modelo definitivo de financiamento das Comunidades Autónomas (CCAA), a demanda de maior autonomía financeira do sistema foi unha constante no Estado das Autonomías. A razón desta demanda está relacionada cos tres grandes alcances da autonomía financeira. $\mathrm{O}$ alcance político, é dicir, a autonomía financeira dota de efectividade á autonomía política. No eido da Facenda Pública, permite ás CCAA configurar unha facenda propia, reducindo a súa dependencia das transferencias da Administración central. Finalmente, no aspecto económicofinanceiro, a autonomía dota ás rexións da capacidade financeira para mellorar o nivel de prestación dos servizos públicos segundo as preferencias dos cidadáns, facendo posible 0 aumento da eficiencia na prestación do gasto público, na medida en que quen é responsable do gasto tamén o é do seu financiamento.

Porén, o sistema de financiamento rexional non avanzou facilmente neste camiño da autonomía financeira, entre outras razóns porque o noso ordenamento xurídico, en concreto, a Constitución, non outorga un papel predominante a este principio fundamental. A autonomía financeira estivo condicionada á realización doutros dous principios, o de solidariedade e o de coordinación. A Constitución, deixando unha ampla marxe para o deseño dun sistema de financiamento, é clara á hora de definir os requisitos que o devandito sistema debe cumprir e que se poderían formular como autonomía solidaria coordinada. O difícil equilibrio entre autonomía, solidariedade e coordinación, e 
as distintas realidades socioeconómicas e políticas das rexións españolas, explican, en gran parte, as dificultades e tensións ás que estivo sometido dende os seus inicios este tema que, por outra banda, é fundamental para o desenvolvemento do Estado das Autonomías.

Dende que se comezou a desenvolver o sistema sempre estivo presente que a capacidade fiscal de cada rexión era distinta e que a igual esforzo fiscal cada rexión obtería uns ingresos tributarios diferentes. Esta é a orixe e a xustificación das transferencias de nivelación, que aínda cobran máis senso nun proceso de descentralización no que a Administración central viña prestando a maior parte das competencias. Os avances na corresponsabilidade fiscal do sistema foron paralelos ao desenvolvemento de mecanismos de nivelación, dando lugar a un sistema tecnicamente máis complexo, pero que non renuncia á solidariedade (entendida, nun senso amplo, como nivelación); unha análise recente desta cuestión pódese atopar en Fernández (2016).

A complexidade do tema fainos centrar a atención nun dos seus múltiples aspectos: a relación entre o exercicio da capacidade normativa cedida e os beneficios fiscais que se obteñen en cada comunidade autónoma. En concreto, o obxectivo deste traballo é analizar as diferenzas existentes entre as CCAA no exercicio da capacidade normativa cedida, o seu impacto nos beneficios fiscais e a súa repercusión sobre o peso dos ingresos tributarios no conxunto de ingresos non financeiros das CCAA. Dos tres alcances da autonomía financeira, o político, o relativo a facenda e o económico, centramos a nosa análise no segundo, ao valorar en que medida a capacidade normativa cedida permite aos gobernos rexionais configurar unha facenda propia. En definitiva, tratamos de achegarnos á efectividade do exercicio da capacidade normativa, que repercusión ten este exercicio sobre as facendas autonómicas?

Para iso, o traballo estrutúrase nas seguintes partes. A continuación, realízase un breve percorrido dos avances do sistema en materia de corresponsabilidade fiscal. No seguinte punto realízanse distintas análises do exercicio da capacidade normativa realizada polas CCAA, comezando por unha análise comparativa do número de medidas vixentes adoptadas polas CCAA, cuxa realización se fundamenta na construción de varios índices que seguen a metodoloxía habitualmente empregada para a elaboración de índices de revelación de información noutros eidos de estudo (Bravo et al. 2009). A continuación, realízase unha análise da súa repercusión sobre os beneficios fiscais e a estrutura de ingresos, abordando expresamente o papel protagonista do IRPF na cesta de tributos cedidos. Todo isto lévase a cabo no período 2012-2014 e en referencia ás CCAA de réxime común. O traballo finaliza cunha discusión e presentación dos resultados obtidos; en concreto, que o exercicio da capacidade normativa sobre tributos cedidos non altera substancialmente a estrutura de ingresos das CCAA, polo que pouco contribúe á configuración dunha facenda propia, como amosa o escaso impacto sobre os beneficios fiscais.

\section{EVOLUCIÓN DA CORRESPONSABILIDADE FISCAL DO SISTEMA DE FINANCIAMENTO AUTONÓMICO}

A autonomía financeira é un concepto máis amplo có de corresponsabilidade fiscal. Sen entrar nunha análise completa de conceptos e da súa interrelación co gasto, do que xa se ocupou amplamente a literatura (Monasterio et al., 1995; Zornoza, 1997; De los Ríos, 2004; Lago e Martínez, 2010), convén esclarecer que a autonomía financeira implica a capacidade de decisión sobre a contía e a estrutura dos ingresos dunha rexión ou comunidade autónoma. Os tres grandes elementos da devandita estrutura de ingresos son os tributos, as transferencias e o endebedamento. Os gobernos rexionais teñen capacidade de decisión, isto é, autonomía, sobre os tributos e o endebedamento, malia que limitada en 
ámbolos dous casos. A corresponsabilidade fiscal fai referencia á obtención de autonomía financeira a través dos tributos ou os ingresos fiscais. Daí que, en adiante, falemos de corresponsabilidade fiscal e non de autonomía financeira.

Por outra banda, a esixencia de igualdade na capacidade de gasto e as diferenzas de renda existentes entre as CCAA españolas, non permiten un deseño do sistema de financiamento autonómico no que todas elas puideran financiarse con tributos propios e cedidos, daí a necesidade de transferencias de nivelación que inevitablemente terán máis peso nas rexións de menor renda (De la Fuente, 2012). É por isto que o principio de corresponsabilidade fiscal deba ser entendido en termos marxinais, é dicir, que os incrementos marxinais de gasto dunha comunidade autónoma sexan financiados por incrementos marxinais de tributos nesa región (De la Fuente, 2012; Cuenca e González, 2014).

É esta capacidade de decisión que as CCAA teñen sobre certos tributos a que dota de contido á corresponsabilidade fiscal. No sistema de financiamento autonómico, a corresponsabilidade fiscal foise concretando en distintas etapas entre as que podemos distinguir:

- Un primeiro período transitorio (1979-1986), no que a corresponsabilidade fiscal das CCAA se centra na capacidade de crear tributos propios e recargos sobre os estatales. Ademais, dende 1983, cando se cede o rendemento dos primeiros tributos estatais, a competencia autonómica exténdese á súa xestión, liquidación, recadación, inspección e revisión.

- O denominado primeiro modelo definitivo de financiamento autonómico, que estivo en vigor no quinquenio 1987-1991, non permitiu que se producira un avance real na corresponsabilidade fiscal do sistema. O financiamento procedía na súa meirande parte das transferencias estatais, en concreto, da Participación nos Ingresos do Estado, para o que se tiñan en conta variables representativas de cada rexión que podían incidir no gasto, ademais das variables esforzo fiscal no IRPF e riqueza relativa que trataba de redistribuír as transferencias entre as CCAA.

- O seguinte quinquenio comezou en 1992 coa encomenda a un grupo de expertos de avanzar na corresponsabilidade fiscal do sistema. Mediante un novo acordo do Consello de Política Fiscal e Financeira, do 7 de outubro de 1993, introdúcese un procedemento para a aplicación da corresponsabilidade fiscal no sistema, que se concretou na participación das CCAA no $15 \%$ das cotas líquidas do IRPF correspondentes ao seu territorio.

- A literatura criticou amplamente que a devandita participación territorializada no IRPF supuxera un avance na corresponsabilidade fiscal, pero o certo é que incrementou a visibilidade dos ingresos tributarios no financiamento do gasto autonómico e supuxo un punto de inflexión na corresponsabilidade fiscal do sistema.

- Realmente, é a partir de 1996 cando se pode falar dun cambio cualitativo e cuantitativo importante na corresponsabilidade fiscal do sistema de financiamento autonómico. A exposición de motivos da Lei 14 / 1996, do 27 de decembro, de modificación parcial da Lei Orgánica 8/ 1980, do 22 de setembro, de Financiamento das Comunidades Autónomas (LOFCA), que dá pé a un novo sistema, recolle que o principio de corresponsabilidade se articula, por unha banda mediante a ampliación da cesión de tributos ás CCAA, en concreto, o IRPF e, por outra, mediante a atribución de competencias normativas. Dúas grandes novidades con respecto ao modelo anterior, non se trata xa dunha participación territorializada no rendemento do IRPF estatal, senón que se cede parcialmente o devandito imposto ás CCAA (30\%), en segundo lugar, a cesión de capacidade normativa sobre os tributos cedidos, sen 
dúbida, un aspecto substancial na corresponsabilidade fiscal, se entendemos por esta a capacidade de decisión sobre tributos.

- O seguinte sistema de financiamento, que se aplicou entre 2002 e 2009, amplía a corresponsabilidade fiscal do sistema ao aumentar a cesión do IRPF dun 30\% a un $33 \%$, e incorpora a cesión do 35\% do IVE territorializado, o 40\% dos impostos especiais e o $100 \%$ do rendemento dos Impostos sobre Vendas Minoristas de Hidrocarburos, Electricidade e o Imposto sobre Determinados Medios de Transporte; amplíanse ademais as competencias normativas sobre o IRPF e sobre os impostos tradicionalmente cedidos. Sobre os novos tributos indirectos cedidos, total ou parcialmente, só se cede ás CCAA competencia para aumentar a tarifa do Imposto sobre Vendas Minoristas de Hidrocarburos e sobre Medios de Transporte.

- Finalmente, o modelo aprobado en 2009 e que continúa vixente, volve incrementar a corresponsabilidade fiscal ao aumentar as porcentaxes de cesión do IRPF e do IVE ata o $50 \%$, dos impostos especiais ata o 58\%, ademais de incrementar as competencias normativas sobre o IRPF e sobre os Impostos sobre Vendas Minoristas de Hidrocarburos e Medios de Transporte; a táboa 1 do anexo resume o alcance da capacidade normativa cedida dende 2009.

O incremento da corresponsabilidade fiscal do sistema tivo distintos alcances. Por unha banda, supuxo un incremento dos recursos financeiros das CCAA, como pon de manifesto o feito de que algunhas CCAA como Madrid, deben devolver parte dos recursos tributarios á facenda central por exceso de financiamento. Por outra banda, supuxo un cambio importante na estrutura dos ingresos non financeiros das CCAA, ao aumentar considerablemente o peso dos ingresos tributarios sobre o total de ingresos non financeiros. Como indican Bassols et al. (2010) a nova cesta de tributos pasa de representar un $68 \%$ dos ingresos autonómicos totais a un $85 \%$, de media.

Atendendo aos ingresos tributarios, habería que distinguir entre tributos propios, tributos cedidos con capacidade normativa e tributos cedidos sen capacidade normativa. A táboa 2 do anexo amosa a representatividade de cada un sobre o total de ingresos tributarios en 2014. De media, os ingresos procedentes de tributos cedidos con capacidade normativa representan un $51,88 \%$ dos ingresos fiscais, namentres que os tributos cedidos sen capacidade normativa representan un 39,43\% e os tributos propios un 8,69\%. Dentro dos tributos cedidos con capacidade normativa, que son o obxecto deste traballo, o IRPF é o que ten maior representatividade cun peso medio do 31,7\% en 2014. Ademais é o tributo cuxa representatividade amosa unha maior variación entre CCAA (desviación típica de $6,21)$.

A cesión de capacidade normativa e o exercicio que as CCAA realizaron dela foi tratado amplamente pola literatura (Cuenca e González, 2014; Durán e Esteller, 2004; Díaz de Sarralde et al. 2005 e Ordóñez e Rivas, 2007, entre outros). Estes traballos puxeron de manifesto que as CCAA empregaron a devandita capacidade normativa para introducir desgravacións, e só algunhas rexións, obrigadas pola redución de ingresos para as arcas públicas que xerou a crise e o peso da débeda, incrementaron a presión fiscal aos seus cidadáns (Cuenca e González, 2014; Ribes, 2012; Durán e Esteller, 2004).

Por outra banda, tamén son varios os traballos que se pronunciaron sobre as condicións necesarias para que as CCAA realicen un exercicio da capacidade normativa que incremente os seus recursos financeiros. Así Cuenca e González (2014) e Ribes (2012) indican que para incentivar a corresponsabilidade fiscal dos gobernos requeriríase sobre todo un compromiso crible de que non haberá novos rescates por parte do Estado, é dicir, acabar coa denominada "restrición orzamentaria branda".

Ademais, no caso da figura tributaria con maior capacidade recadadora, o IRPF, o sistema de financiamento vixente non incentiva o exercicio da capacidade normativa cedida 
debido ao mecanismo de entregas a conta que cada ano asigna ás CCAA unha previsión por IRPF que é liquidada dous años máis tarde. Isto implica que as medidas tributarias adoptadas polas comunidades para 0 ano $\mathrm{n}$ non se aplican aos contribuíntes ata 0 momento de presentar a súa declaración (nos meses de maio e xuño do ano $n+1$ ), e non teñen efectos recadadores ata o exercicio seguinte $(n+2)$. Deste xeito, os incentivos para adoptar medidas que incrementen a recadación son moi febles (Cuenca e González, 2014).

\section{METODOLOXÍA DA ANÁLISE DO EXERCICIO DA CAPACIDADE NORMATIVA}

Co obxectivo de analizar as diferenzas existentes entre as CCAA no exercicio da capacidade normativa cedida, así como o impacto deste nos beneficios fiscais derivados das medidas adoptadas e na estrutura de ingresos non financeiros das distintas rexións, levamos a cabo unha análise descritiva en varias etapas. En primeiro lugar, e empregando para iso a metodoloxía utilizada habitualmente para a elaboración dos índices de divulgación de información (Bravo et al. 2009), elabóranse distintos indicadores que representan o grao de actividade relativo das CCAA no exercicio das súas competencias normativas. Ao se tratar de índices numéricos, é doado comparar ás CCAA.

Na literatura previa empregáronse outras metodoloxías para medir a intensidade regulatoria. Por exemplo, Marcos et al. (2010) elaboran tres índices co obxecto de medir a actividade e intensidade na regulación por parte das CCAA españolas no período comprendido entre 1978 e 2009. Os autores elaboran estes índices a partir do número de páxinas publicadas nos boletíns oficiais e o número de leis aprobadas por cada CCAA. Entre os traballos sobre corresponsabilidade fiscal das CCAA cabe destacar o realizado por Atienza e Hierro (2005), que constrúen un índice para medir a corresponsabilidade fiscal dos tributos cedidos tendo en conta se se cede o rendemento (total ou parcial), as competencias en canto á xestión do tributo e as competencias normativas.

Nunha segunda fase, o grao en que as CCAA exerceron a capacidade normativa cedida compárase cos beneficios fiscais que afectan aos tributos con capacidade normativa. Da análise dos ingresos tributarios das CCAA realizado no apartado 2 cabe concluír que 0 IRPF é o tributo con capacidade normativa que presenta unha maior capacidade recadadora motivo polo cal centramos a análise sobre a devandita figura. En concreto, mediante unha análise descritiva e unha análise clúster relacionamos o índice de medidas normativas adoptadas sobre o IRPF, os beneficios fiscais derivados das mesmas e a representatividade do devandito tributo nos ingresos tributarios.

A metodoloxía empregada permite identificar diferenzas existentes entre rexións en canto á repercusión ou impacto do exercicio da capacidade normativa sobre os beneficios fiscais e, asemade, permite analizar a estabilidade da representatividade das figuras tributarias no período de estudo.

a. Determinación da poboación obxecto de estudo

A poboación obxecto de estudo está constituída polas quince CCAA de réxime común e abrangue o período comprendido entre 2012 e 2014, inclusive os dous. O ámbito espacial ao que se refire o estudo comprende, polo tanto, ás CCAA que teñen atribuída a mesma capacidade normativa sobre os impostos cedidos. Pola súa banda, o eido temporal no que se circunscribe este traballo refírese, por unha banda, á información máis actual dispoñible ata a data de realización do mesmo e, por outra, coincide coa vixencia da última Lei 22/ 2009, do 18 de decembro, na que se regulan, entre outros aspectos, as entregas a conta do IRPF de cada ano, de modo que se asigna ás CCAA unha previsión por IRPF que será liquidada dous anos máis tarde.

b. Fonte de datos

Os datos relativos ao exercicio de competencias normativas sobre os impostos cedidos obtivéronse dos cadros-resumo publicados anualmente polo Ministerio de Facenda e 
Administracións Públicas (en adiante, MINHAP) na súa publicación electrónica "Tributación Autonómica"1. En particular, o capítulo 1 da citada publicación recolle as liñas de actuación das CCAA tanto sobre os tributos cedidos como sobre os tributos propios e presenta, ao final do mesmo, unha serie de anexos que recollen de forma detallada todas as medidas vixentes adoptadas por cada goberno autonómico en materia de tributos cedidos. A información relativa aos beneficios fiscais derivados do exercicio da capacidade normativa obtivéronse accedendo a través das páxinas web das distintas CCAA.

C. Índice de medidas vixentes

Para analizar o grao de intensidade co que as CCAA exerceron as competencias normativas nos tributos cedidos sobre os que teñen capacidade, construíronse dous índices: un índice global non ponderado (INP) e un índice ponderado (IP).

$\mathrm{O}$ obxectivo da utilización destes índices é medir o nivel relativo de exercicio das competencias normativas por parte de cada unha das CCAA. Ámbolos dous índices están deseñados seguindo a metodoloxía utilizada na literatura previa para a construción de índices de revelación voluntaria ou obrigatoria de información, é dicir, como indicadores numéricos representativos da cantidade de medidas vixentes adoptadas por cada comunidade autónoma en cada período sobre o número máximo de medidas posibles que podería ter adoptado. Deste xeito, estes índices son útiles como indicadores do grao de exercicio relativo das competencias normativas.

A elaboración dos índices levouse a cabo a partir das seguintes etapas:

1) Identificación das partidas que compoñen o índice.

A través da análise dos cadros-resumo publicados polo MINHAP, identifícanse as medidas aprobadas, cada unha das cales constitúe unha partida ou ítem (i) que se empregará para a construción do índice. Así, da análise realizada identificáronse un total de 175 medidas vixentes nas comunidades de réxime común durante o período estudado (2012 a 2014). Porén, existen 14 medidas que non son aplicables a todas as CCAA en todos os exercicios (p.e. deducións no IRPF por traslado a outra illa) polo que estas son axustadas de forma tal que o número máximo de medidas fiscais posibles que podería adoptar calquera comunidade ascende a 161. As medidas identificadas clasifícanse en categorías en función do tipo de imposto ao que se refiran. A táboa 1 amosa a distribución das partidas ou ítems por tipo de imposto. Así, por exemplo, con respecto ao IRPF, as CCAA aprobaron en total 35 medidas fiscais aínda que 3 delas non son consideradas na construción do índice porque non son aplicables a todas as CCAA.

2) Valoración das partidas ou ítems

A cada unha das partidas ou ítems asignállese o valor 1 se é unha medida que a comunidade autónoma mantén vixente no período analizado e o valor 0 no caso contrario.

3) Elaboración do índice non ponderado (INP).

Con respecto ao INP, partindo do número máximo de medidas posibles por tipo de imposto identificadas na etapa 1 e da valoración de cada unha delas na etapa 2 , elaborouse un índice non ponderado para cada categoría (tipo de imposto) así como un índice non ponderado global $\mathrm{INP}_{\mathrm{jt}}$. Estes índices son o resultado de dividir o número total de medidas i que a comunidade autónoma j aprobou no período t entre o número máximo de medidas posibles. Onde $\mathrm{INP}_{\mathrm{jt}}$ é o índice non ponderado que mide o grao de actividade relativa das CCAA en canto ao exercicio das súas competencias sobre os tributos cedidos.

1 Accesible a través de http:// www.minhap.gob.es/ es-

ES/ Areas\%20Tematicas/ Financiacion\%20Autonomica/ Paginas/ libro\%20electronico\%20tribut acion.aspx 
$\mathrm{d}_{\mathrm{i}, \mathrm{j}, \mathrm{t}}$ indica se a CCAA j exerceu capacidade a través da aprobación da medida i no período $t$, sendo $\mathrm{i}=1, \ldots, 161$ para o índice global e $\mathrm{i}=1, \ldots ., \mathrm{n}$ para cada un dos índices por tipo de imposto (sendo n o número total de medidas posibles para cada tipo de imposto). Deste xeito, $\mathrm{d}_{\mathrm{i}, \mathrm{j}, \mathrm{t}}$ toma valor 1 se a CCAA $\mathrm{j}_{\mathrm{j}}$ mantén vixente a medida fiscal $\mathrm{i}$ no período $\mathrm{t}$ e 0 , ao contrario.

4) Elaboración do índice ponderado global (IP).

A importancia de cada un dos tributos cedidos sobre os que as CCAA poden introducir modificacións fiscais sobre o total de ingresos tributarios non é homoxénea tal e como amosa a táboa 2 do Anexo.

Táboa 1: Número máximo de medidas fiscais posibles que poderían adoptar as CCAA

\begin{tabular}{|l|r|r|r|}
\cline { 2 - 4 } \multicolumn{1}{c|}{} & \multicolumn{3}{c|}{ № partidas ou ítems } \\
\hline \multicolumn{1}{c|}{ Tipo de imposto } & Iniciais & Axuste & Definitivas \\
\hline IRPF & 35 & $(3)$ & 32 \\
ISD & 53 & $(3)$ & 50 \\
IP & 6 & - & 6 \\
ITP & 37 & $(4)$ & 33 \\
AJD & 29 & $(4)$ & 25 \\
IDMT & 7 & - & 7 \\
IH & 8 & - & 8 \\
\hline Total & 175 & $(14)$ & 161 \\
\hline
\end{tabular}

Fonte: Elaboración propia a partir de información obtida do MINHAP.

Táboa 2: Elaboración do índice non ponderado (INP)

\begin{tabular}{|c|c|c|}
\hline \multicolumn{2}{|c|}{ Índice INP por categorías } & Índice INP global \\
\hline$I N P_{I R P F_{j t}}=\frac{1}{32} \sum_{i=1}^{32} d_{i, j, t}$ & $I N P_{A j D_{j t}}=\frac{1}{25} \sum_{i=1}^{25} d_{i, j, t}$ & \\
\hline$I N P_{I S D_{j t}}=\frac{1}{50} \sum_{i=1}^{50} d_{i, j, t}$ & $I N P_{I D M T_{j L}}=\frac{1}{7} \sum_{i=1}^{7} a_{i, j,}$ & $1 \stackrel{161}{16}^{-16}$ \\
\hline$I N P_{I P_{j t}}=\frac{1}{6} \sum_{i=1}^{6} d_{i, j, t}$ & $I N P_{I H}=\frac{1}{8} \sum_{i=1}^{9} d_{i, j}$ & $101 \sum_{i=1}$ \\
\hline & $I N P_{I T P_{j} t}=\frac{1}{33} \sum_{i=1}^{32} d_{i, j, t}$ & \\
\hline
\end{tabular}

Fonte: elaboración propia 
En consecuencia, poden existir diferenzas significativas na repercusión fiscal das modificacións que as CCAA poden introducir sobre os tributos cedidos. Por exemplo, a importancia do IRPF no conxunto de ingresos tributarios é moito maior cá do resto de tributos cedidos na meirande parte das CCAA, polo que as medidas adoptadas con respecto ao IRPF deberían ter unha maior ponderación no cálculo do índice global cás adoptadas para o resto de tributos. Por este motivo, considerouse necesario calcular un índice ponderado que tome en consideración a importancia de cada un dos tributos sobre o total de ingresos orzamentarios de carácter fiscal.

Para a elaboración do índice ponderado global (IP) asígnase aos índices non ponderados (INP) calculados para cada tributo un peso distinto, representativo da importancia do tributo sobre o total de tributos cedidos con competencia normativa.

Deste xeito, o índice $\mathrm{IP}_{\mathrm{jt}}$ calcúlase aplicando a ponderación $\mathrm{p}$ asignada a cada tributo $\mathrm{K}$ ao INP calculado para esa categoría ou tributo (INP_K) na CCAAj durante o período t:

\section{Ecuación 1}

$I P_{j t}=\sum I N P_{K, t} \times p_{K, j, t}$

\section{RESULTADOS}

Os índices expostos construíronse para cada un dos anos do período de estudo 20122014.

A táboa 3 recolle os valores medios correspondentes a: o índice non ponderado global (INP), o índice non ponderado do IRPF (INP IRPF) e o índice ponderado (IP). Os valores preséntanse ordenados de maior a menor vālor, de forma tal que valores máis (menos) elevados do índice amosan un maior (menor) grao de intensidade no exercicio das súas competencias normativas, obtendo así tres ránkings de CCAA en relación ao exercicio realizado da capacidade normativa cedida.

Os valores do índice non ponderado poñen de manifesto en primeiro lugar que o grao co que as CCAA exerceron as súas competencias normativas é dispar. En particular, Cataluña é a comunidade autónoma cun maior número relativo de medidas vixentes e Murcia e A Rioxa, as que presentan menores valores do índice. Cataluña, Galicia, Baleares, Cantabria e Extremadura que aparecen como as CCAA máis activas en función do índice non ponderado xeral, non o son na ordenación con respecto ao índice ponderado e ao do IRPF. Isto é indicativo de que nestas CCAA o exercicio da capacidade normativa centrouse noutros tributos e non tanto no IRPF. Pola contra, Castela e León, Valencia, Andalucía eAsturias resultan ser máis activas na ordenación en función do índice ponderado e do IRPF que con respecto ao non ponderado, o que indica que na súa actividade normativa 0 IRPF mantén un número relativamente importante de medidas vixentes.

Para avanzar nesta análise, compárase o grao en que as CCAA exerceron a capacidade normativa cedida cos beneficios fiscais (BF) (véxase a táboa 3 do anexo). Ademais, dado que o IRPF é o instrumento tributario con maior capacidade recadadora, centramos esta análise nesta figura. 
Táboa 3. Ordenación das CCAA en función do valor do índice de medidas adoptadas

\begin{tabular}{|l|c|l|c|l|c|}
\hline \multicolumn{2}{|c|}{$\begin{array}{c}\text { Índice Non Ponderado } \\
\text { (INP) }\end{array}$} & \multicolumn{2}{|c|}{ Índice Ponderado } & \multicolumn{2}{c|}{$\begin{array}{c}\text { Índice Non Ponderado IRPF } \\
\text { (INP IRPF) }\end{array}$} \\
\hline Cataluña & 0,416 & Castela León & 0,391 & Castela León & 0,417 \\
\hline Galicia & 0,41 & Valencia & 0,367 & Valencia & 0,417 \\
\hline Baleares & 0,408 & Andalucía & 0,36 & Andalucía & 0,396 \\
\hline Cantabria & 0,377 & Asturias & 0,354 & Asturias & 0,354 \\
\hline Extremadura & 0,362 & Canarias & 0,329 & Canarias & 0,344 \\
\hline Asturias & 0,329 & Galicia & 0,328 & Madrid & 0,333 \\
\hline Valencia & 0,319 & Extremadura & 0,328 & Galicia & 0,292 \\
\hline Castela León & 0,317 & Madrid & 0,315 & Extremadura & 0,292 \\
\hline Canarias & 0,315 & Baleares & 0,296 & Aragón & 0,292 \\
\hline Andalucía & 0,308 & Murcia & 0,293 & Baleares & 0,271 \\
\hline Madrid & 0,290 & Aragón & 0,285 & $\begin{array}{l}\text { Castela A } \\
\text { Mancha }\end{array}$ & 0,25 \\
\hline $\begin{array}{l}\text { Castela A } \\
\text { Mancha }\end{array}$ & 0,288 & Castela A Mancha & 0,284 & Cataluña & 0,24 \\
\hline Aragón & 0,267 & Cataluña & 0,283 & Cantabria & 0,208 \\
\hline Murcia & 0,246 & Cantabria & 0,277 & A Rioxa & 0,156 \\
\hline A Rioxa & 0,207 & A Rioxa & 0,175 & Murcia & 0,156 \\
\hline Valor medio & 0,324 & Valor medio & 0,311 & Valor medio & 0,295 \\
\hline Desv. Típica & 0,062 & Desv. Típica & 0,051 & Desv. Típica & 0,084 \\
\hline
\end{tabular}

Fonte: elaboración propia

Unha primeira conclusión é que un valor máis alto do índice, é dicir, un maior exercicio da capacidade normativa sobre o IRPF non se corresponde necesariamente con maiores beneficios fiscais, de feito ao analizar a correlación entre as dúas variables, o índice e a proporción de beneficios fiscais sobre o orzamento do IRPF, esta era negativa, malia que non estatísticamente significativa. Independentemente de que as CCAA empregaran a capacidade normativa para incrementar a recadación ou para otros fins como dar contido a políticas sociales, o certo é que os datos amosan que os beneficios fiscais son pouco significativos en termos relativos (medidos sobre a recadación orzamentada de IRPF). É por iso, que como se analiza máis adiante, o peso dos tributos e, en concreto, do IRPF, sobre os ingresos non financeiros non varía substancialmente.

Para profundar no comportamento das CCAA realizouse unha análise clúster, o que permitiu identificar dous grupos diferenciados de CCAA. 
Táboa 4. Análise da varianza

\begin{tabular}{|c|c|c|c|c|c|c|}
\hline & \multicolumn{2}{|c|}{ Clúster } & \multicolumn{2}{|c|}{ Erro } & \multirow[b]{2}{*}{$\mathrm{F}$} & \multirow[b]{2}{*}{ Sig. } \\
\hline & $\begin{array}{c}\text { Media } \\
\text { cadrática }\end{array}$ & gl & $\begin{array}{c}\text { Media } \\
\text { cadrática }\end{array}$ & $g l$ & & \\
\hline Índice IRPF (INP IRPF) &, 012 & 1 & 009 & 40 & 1,375 & ,248 \\
\hline $\mathrm{BF} / \mathrm{IRPF}$ & 871 & 1 & 002 & 40 & 358,102 & 000 \\
\hline IRPF/ Ingresos tributarios & 004 & 1 & 004 & 40 & ,928 & 341 \\
\hline
\end{tabular}

Fonte: elaboración propia (SPSS)

Como amosa a análise da varianza (táboa 4), das tres variables empregadas (índice non ponderado para IRPF, ratio beneficios fiscais sobre IRPF e ratio IRPF sobre ingresos tributarios), a ratio dos beneficios fiscais sobre o IRPF resulta ser significativo á hora de explicar a formación de grupos. Dos dous grupos identificados, un está formado por Asturias, Cataluña e A Rioxa, o outro clúster recolle o resto de CCAA. Atendendo aos centros dos conglomerados (táboa 5) obsérvase que a diferenza entre os dous grupos se debe a que no grupo máis reducido a ratio beneficios fiscais sobre IRPF é maior có valor do índice do IRPF, é dicir, o exercicio da capacidade normativa sobre o IRPF traduciuse en termos relativos, en maiores beneficios fiscais neste grupo de rexións cá no resto. Advírtase que non son as rexións que realizaron un maior uso da capacidade normativa, os valores do índice do IRPF non son dos máis altos, incluso no caso da Rioxa é dos máis baixos. É dicir, hai un grupo reducido de tres CCAA que non realizaron un uso intenso da capacidade normativa pero cuxas medidas tiveron un maior impacto nas arcas autonómicas, namentres que hai unha maioría de CCAA que realizan un exercicio moi activo da capacidade normativa cedida que case non impacta nas arcas autonómicas.

Táboa 5. Centro dos conglomerados finais

\begin{tabular}{|l|r|r|}
\hline \multirow{2}{*}{} & \multicolumn{2}{|c|}{ Clúster } \\
\cline { 2 - 3 } & 1 & \multicolumn{1}{|c|}{2} \\
\hline Índice IRPF (INP_IRPF) &, 26172 &, 30423 \\
\hline BF/ IRPF &, 39643 &, 02966 \\
\hline IRPF/ Ingresos tributarios &, 3667 &, 3413 \\
\hline
\end{tabular}

Fonte: elaboración propia (SPSS)

A análise das medidas adoptadas en 2014 por estas tres CCAA non permite extraer conclusións adicionais, xa que namentres Cataluña e Asturias incrementaron a tarifa do IRPF por encima da estatal, A Rioxa regulou unha tarifa inferior á estatal. En canto ao número de deducións, A Rioxa é a que establece un número menor, por nacemento ou adopción de fillos, por adquisición de vivenda habitual para determinados colectivos, por adquisición ou rehabilitación da vivenda habitual e por vivendas rurais que se convirtan en residencia habitual do contribuínte. Asturias é a que incorpora un maior número de deducións das tres (catro tipos diferentes de deducións por circunstancias persoais ou familiares, outras 4 relacionadas coa vivienda habitual, unha por doazóns, outra por fomento do emprego e outra pola obtención do certificado de xestión forestal sostible). Cataluña recolle dous tipos diferentes de deducións por circunstancias persoais ou 
familiares, dúas relacionadas coa vivienda habitual, outras dúas relacionadas con doazóns e dúas máis correspondentes a deducións por estudos e adquisición de libros de texto, así como por adquisición de accións ou participacións sociais en determinadas entidades.

Detrás do impacto destas medidas están factores socioeconómicos como a distribución da renda nas devanditas rexións e, polo tanto, os colectivos afectados polas decisións tributarias sobre o IRPF. Porén, non é o noso obxectivo valorar a efectividade das medidas adoptadas sobre as políticas sociais ou a distribución da renda en cada comunidade, senón o seu impacto sobre a configuración da facenda autonómica.

Os datos da táboa 4 do anexo tratan de aproximarnos a devandita configuración. Atendendo á importancia da recadación por IRPF sobre o total de ingresos tributarios, a primeira conclusión que se desprende é o descenso xeral da representatividade deste tributo a pesar de que varias CCAA exerceron a súa capacidade normativa para incrementar a tarifa autonómica (Cataluña, Andalucía, Asturias, Cantabria, Canarias e Extremadura). Esta redución do peso do IRPF no conxunto do sistema é debida fundamentalmente á perda recadadora derivada dunha menor actividade económica en momentos de crise. Porén, a proporción da recadación por tributos sobre o total de ingresos orzamentarios non financeiros e tamén sobre os ingresos orzamentarios totais mantivéronse máis estables. En definitiva, esta análise pon de manifesto que a autonomía financeira, medida como a porcentaxe de ingresos tributarios sobre outro tipo de recursos, depende fundamentalmente da cesta de tributos cedidos e da porcentaxe de rendemento cedido, namentres que a cesión de capacidade normativa apenas afecta á configuración dos ingresos autonómicos, malia que no caso das CCAA que incrementaron a tarifa do IRPF puido compensar unha maior redución dos seus ingresos tributarios, a cambio dunha maior presión fiscal sobre os seus cidadáns.

\section{DISCUSIÓNE CONCLUSIÓNS}

O desenvolvemento do sistema de financiamento procurou aumentar a corresponsabilidade fiscal atribuíndo maiores competencias normativas nos tributos cedidos ás CCAA. Porén, tal como recolle a literatura e, en parte, amósase neste traballo, non parece que as CCAA fixeran uso destas competencias para aumentar a recadación co obxectivo de financiar os incrementos no gasto. Malia que isto é certo, hai que recoñecer que a crise económica e o excesivo endebedamento animaron a algúns gobernos rexionais a incrementar a tarifa do IRPF e a incorporar outras medidas de subida de tipos e tarifas noutros tributos cedidos, pero non co obxectivo de financiar os incrementos de gasto (corresponsabilidade fiscal) senón co ánimo de compensar a perda recadadora que a diminución das bases, como consecuencia dunha menor actividade económica, provocaría. O traballo pon de manifesto que as CCAA realizaron un uso intenso malia que dispar da capacidade normativa cedida, pero que este exercicio non repercute en grandes beneficios fiscais, nin altera substancialmente a estrutura de ingresos orzamentarios das CCAA, polo que pouco contribúe á configuración dunha facenda propia. Porén, este exercicio si repercute sobre a cidadanía de cada rexión xerando presións fiscais distintas. Tan só un grupo reducido de CCAA (Cataluña, Asturias e A Rioxa) presenta un impacto relativo maior das medidas tributarias adoptadas sobre os beneficios fiscais; o que debería ser xeneralizado, é máis ben unha excepción de tres casos.

A análise presentada neste traballo non está exento de limitacións. En primeiro lugar, hai que ter en conta que no sistema de financiamento uns elementos están relacionados con outros, polo que somos conscientes da limitación que supón abordar a corresponsabilidade fiscal e a autonomía financeira independentemente das transferencias de nivelación. Así mesmo, non foi o noso obxecto valorar a idoneidade da 
actual composición da cesta de tributos cedidos, nin da capacidade normativa que as CCAA teñen sobre eles.

Por outra banda, con respecto á metodoloxía empregada, a principal limitación é que os índices construídos só contemplan o número relativo de medidas adoptadas polas CCAA, sen ter en conta o carácter gravatorio ou desgravatorio das devanditas medidas. En contraposición, os índices teñen a vantaxe de posibilitar a comparación entre CCAA e a elaboración de ránkings. Ademais, con estes índices pódense utilizar técnicas estatísticas para analizar os factores que inflúen en diferentes niveis de actividade normativa, ao poderse tratar como variables dependentes en modelos econométricos.

Polo tanto, este traballo lévanos a formular unha nova liña de investigación sobre os factores socioeconómicos que poden estar detrás dos diferentes niveis de exercicio da capacidade normativa cedida aos gobernos autonómicos e como o uso desta capacidade normativa repercute non tanto na política recadadora canto noutras políticas autonómicas, como a social.

\section{BIBLIOGRAFIA}

Atienza, P. y Hierro, L. A. (2005): “¿Hasta dónde la corresponsabilidad fiscal en el sistema español de financiación autonómica de régimen común? Un ejercicio de comparación con el caso canadiense". Revista de Estudios Regionales, 74, 43-87.

Bassols, M. Bosch, N. y Vilalta, M. (2010): El modelo de financiación autonómica de 2009: descripción y valoración. Generalitat de Catalunya, Monografía, 13.

Bravo, F. Abad, C. y Trombetta, M (2009): "Disclosure índices design: does it make a diference?" Revista de Contabilidad-Spanish Accounting Review, 12 (2) , 253-278.

Cuenca, A. y González, R. (2014): Cesión del 100\% del IRPF a las CCAA. Fundación de las Cajas de Ahorros, Documento de Trabajo, 760.

De la Fuente, A. (2012): El nuevo sistema de financiación de las CCAA de régimen común: un análisis crítico y datos homogéneos para 2009 y 2010. BBVA Research. Documentos de Trabajo. 12/ 23, Madrid.

Díaz de Sarralde, S.; Sánchez, J. M. y Torrejón, L. (2006): “La capacidad normativa en los tributos cedidos a las CCAA: situación actual y vías de reforma”, Análisis Local, 65, 47-60.

Durán, J. Ma y Esteller, A. (2004): El ejercicio de la capacidad normativa de las CCAA en los tributos cedidos: una primera evaluación a través de los tipos impositivos efectivos en el IRPF. Instituto de Estudios Fiscales, Documento de Trabajo 20.

Fernández, X. (2016): “Crisis y modelo de financiación autonómica 2009: lecciones para el futuro". Revista Galega de Economía, vol 25, 2, 25-47.

Lago, S. y Martínez, J. (2010): “La descentralización tributaria en las CCAA de régimen común: un proceso inacabado". Hacienda Pública Española, 192, 129-151.

Marcos, F.; Santaló, J.; Sánchez-Graells, A. (2919): "Measuring regulatory intensity by the Spanish Regions (1978-2009)”. Revista para el Análisis del Derecho, 4, 1-39.

Monasterio, C.; Pérez, C.; Sevilla, J.V.; Sole, J. (1995): Informe sobre el actual sistema de financiación autonómica y sus problemas. IEF, Madrid.

Ordóñez, C. y Rivas, C. (2007): "Los tributos cedidos a las CCAA: Dinámica de la capacidad normativa en el periodo 19972006". Revista de Estudios Regionales, 78, 291-305.

Ribes, A. (2012): Poder normativo y autonómico y tributos cedidos, Ed. Tirant lo Blanch, España.

Zornoza, J.J. (1997): “Corresponsabilidad fiscal y financiación de las CCAA: el modelo para el quinquenio 1997-2001". En AAVV El Estado de las Autonomías. Centro de Estudios Ramón Areces, Madrid, tomo IV, págs. 4021 y ss.

Anexo on line: https:/ / ideas.repec.org/ s/ sdo/ regaec.html 